\title{
DYNAMIC OF POPULATION-DYNAMICS IN A MEDICALLY IMPORTANT SNAIL SPECIES LYMNAEA (RADIX) LUTEOLA (LAMARCK)
}

\author{
T. K. MISRA \& S. K. RAUT
}

\author{
Ecology and Ethology Laboratory, Department of Zoology, University of Calcutta, 35 Ballygunge \\ Circular Road, Calcutta 700019, India
}

The life-cycle parameters of the snail Lymnaea (Radix) luteola and the factors influencing the same have been studied under laboratory conditions. In each month, from July 1990 to June 1991, a batch of 100 zero-day old individuals were considered for studies. The snails of April batch survived for 19.42 days while those in December batch survived for 87.45 days. The May batch individuals though survived for 65.67 days gained maximum shell size $(15.84 \mathrm{~mm}$ in length) and body weight (419.87 mg). All individuals of April batch died prior to attainment of sexual maturity. In the remaining 11 batches the snails became sexually mature between 32 and 53 days. At this stage, they were with varying shell lengths, $9.3 \mathrm{~mm}$ to $13.11 \mathrm{~mm}$ in respect to batches. The reproduction period varied from 1-67 days. An individual laid, on an average, 0.25 (March batch) to 443.67 (May batch) eggs in its life-span. A batch of such snails would leave $24312,22520,720268,80408,76067,418165,214,9202,0,0,2459386$ and 127894 individuals at the end of 352 nd day. Since the environmental conditions were almost similar the 'dynamic' of population dynamics seems to be involved with the 'strain' of the snail individuals of the batches concerned.

Key words: Lymnaea (Radix) luteola - growth - natality - mortality - productivity - dynamic --
population - dynamics

Snail-borne diseases of men and animals are burning problems throughout the world. The role of certain freshwater snail species in mediating such diseases is well established. Considering the severity of these diseases various attempts are being made to control the snail-hosts by different means but the results are not encouraging. Now-a-days, to avoid environmental hazards, attention is being paid more towards the development of biological control device than the process of standardization needed for application of chemicals. Even, after gaining sufficient knowledge on the biology of certain snail species from the laboratory studies of numerous workers, it is not being possible to keep the population densities of the concerned snail species in check through the use of effective controlling agents. The possible reasons behind such failures are being discussed by the workers from time to time. Since, in most cases, the host-snail species are continuous breeders and there is every possibility of getting a good number of individuals

Received 10 December 1992.

Accepted 14 June 1993. of different ages distributed in pre-reproductive, reproductive and post-reproductive groups, data on the trend of population growth at different time points are essential to ascertain the dynamics of the target snail population and the factors, rather the 'dynamic' involved with the same. To-date, no such attempt is on record. As the snails belonging to Lymnaeidae have a world-wide distribution and their role in spreading worm diseases is the objective of serious concern, an attempt was made to study the population dynamics of the lymnaeid snail Lymncea (Radix) luteola (Lamarck) occurring in and around Calcutta, West Bengal, India. Keeping in view to note the dynamic triggering the population dynamics of the said snail species in respect to time of the year concerned, the possible factors influencing the process are also taken into account in the course of experimental studies under laboratory conditions.

\section{MATERIALS AND METHODS}

With a view to get the newly hatched individuals for experimental studies a good num- 
ber of sexually mature $L$. (R.) luteola were collected from the pond located in the Ballygunge Science College Campus, Calcuta University, Calcutta during June, 1990. They were released into a plastic container $(26 \mathrm{~cm}$ in diameter) containing 3.5-4.0 1 of water collected from the same pond. A few examples of Chara, Vallisneria, Hydrilla and Ipomoea were also released into the water of the container to provide resting as well as egg laying sites for the snails. The snails were supplied with lettuce (Lactuca sativa) regularly as food. The water of the container was changed regularly by fresh pond water. The unconsumed part of lettuce, dead snails if any and faecal pellets were also removed regularly, at an interval of $24 \mathrm{hr}$. The snails started egg laying from the very next day. The egg capsules were collected regularly. They were then kept in small glass beakers and dated. The eggs hatched within a few days. The newly hatched (zeroday old) snails thus obtained were considered for the following studies.

A total of 12 sets of experiments were designed to study the life cycle parameters of L. (R.) luteola. For each experiment 100 newly hatched (zero-day old) individuals were considered. In all cases, for the convenience of studies, at the initial state, for a period of two weeks they were maintained in a glass beaker containing $750 \mathrm{ml}$ pond water. After that, that is, on and from the third week, the snails were transferred to a plastic container $(26 \mathrm{~cm}$ in diameter and $14 \mathrm{~cm}$ in depth) containing 3.5 4.01 water. The 12 sets of experiments were designed to record the variability, if any, in the life cycle parameters of $L$. (R.) luteola borne during the first week of each month from July 1990 to June 1991. And as such, depending on the availability of the required number of newly hatched (zero-day old) snails, the experiments were initiated on July 1, August 1, September 1, October 4, November 4, December 6 of 1990 and January 7, February 5, March 3, April 2, May 1 and June 1 of 1991. The snails considered for experimental studies were maintained carefully until the last individual of each experiment was died. Throughout the experiment pond water was used and mustard (Brassica nigra) leaves were supplied to the snails as food. A strict hygienic condition was maintained throughout by removing the unconsumed food materials, by changing water along with the dead snail individuals, if any, and the feacal pellets regularly, at an interval of $24 \mathrm{hr}$.
In the course of studies weekly measurements on the rate of growth in shell length, shell breadth and in total body weight of $L$. (R.) luteola have been taken from any ten individuals, selected at random from the experimental set. In cases where the number of snails was reduced to nine and/or below, the data were taken only from the available individuals of the respective experimental set. A mean of such ten (sometimes less) readings was considered as the final data. Also, in the course of studies on the growth rates in $L$. $(R$.) luteola, attention was given to note the shell length, shell breadth and total body weight of the individuals at the time of first egg-laying. In all sets of experiment attention was given to note the age of the individuals at the time of first egg laying, the number of egg capsules produced, the number of eggs present in each capsule and the age of the individuals on the day of deposition of the last egg capsule. Simultaneously, data on the age of each and all individuals on the day of death, the time required for hatching eggs and the hatchability of eggs have been noted regularly.

To ascertain the influence of physico-chemical factors on the life cycle parameters of $L$. (R.) luteola, water used in each and all experiments was analyzed and the concentrations of chloride, hardness (as determined by $\mathrm{CaCO}_{3}$, $\mathrm{Ca}^{++}$and $\mathrm{Mg}^{++}$) and alkalinity were determined following the methods described in Trivedy \& Goel (1986). Data on temperature of surface water of the container and the $\mathrm{pH}$ of said water were taken regularly.

Statistical analysis of the data has been made following Goon et al. (1987). Throughout the text, the values given following \pm (plus/ minus) indicate standard error (S.E.).

\section{RESULTS}

Marked variations in growth rates and in life cycle parameters have been noted in the snail $L$. (R.) luteola in respect to the set of experiments. Of the 12 sets of experiments the snails considered for studies on 2 April 1991 did not survive beyond 60 days. Moreover, they were unhealthy throughout and $50 \%$ individuals died within 16 days. None of them attained sexual maturity.

The snails exhibited a varying rate of growth in shell length, shell breadth and total body weight (Fig. 1). The maximum and minimum 

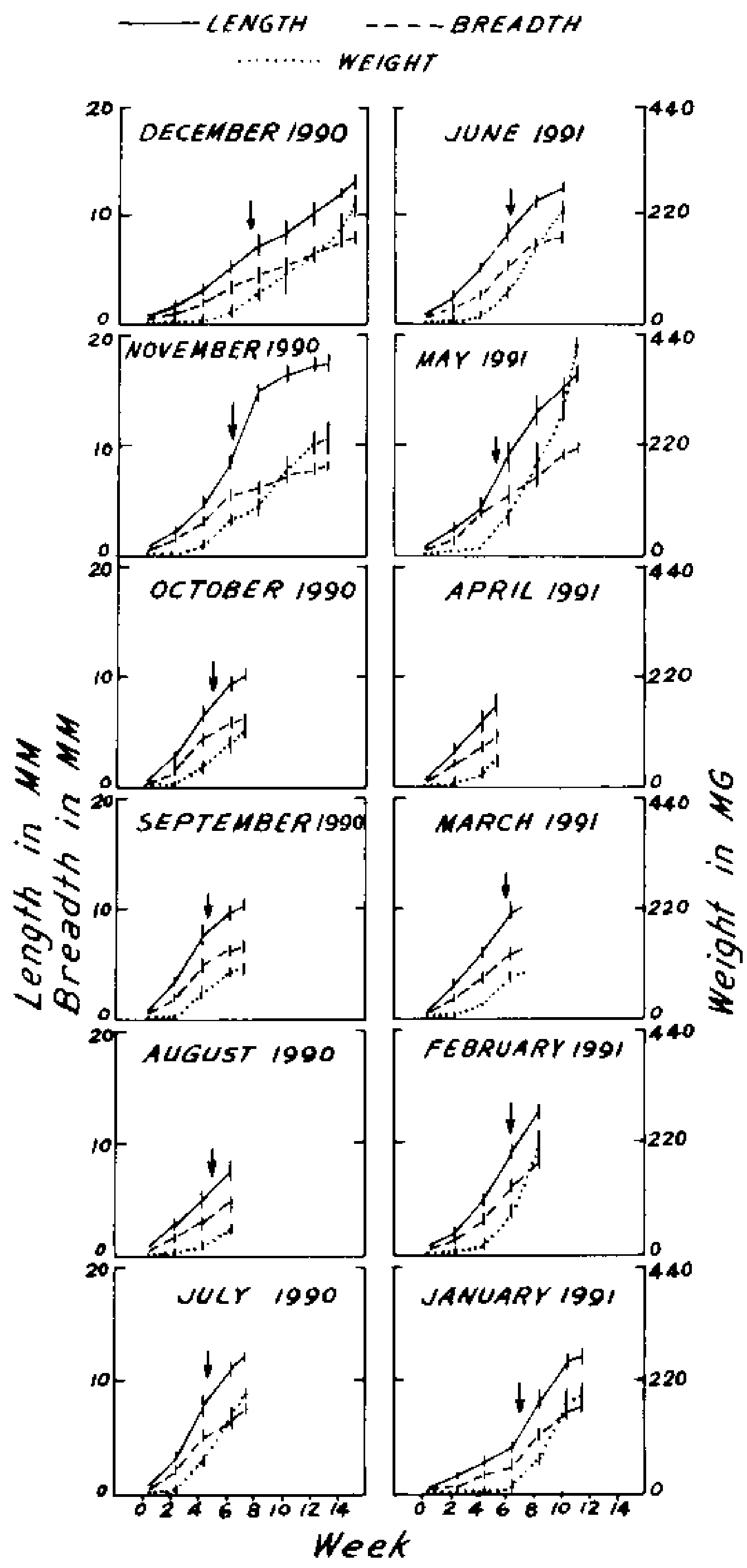

Fig. I: bi-weekly growth rates in Lymnata (Radiv) /uteola during the entire life span of the individuals selected for studies. [For experiment 100 zero-day old individuals were considered for studies by the first week of each month and they were maintained separately, in respect to the batch of the snail and months concerned]. Arrows indicate the initiation of egg laying. Vertical lines indicate S.E.

addition to the length of the shell, breadth of the shell and to the weight of the body were $1.63 \mathrm{~mm}, 0.99 \mathrm{~mm}$ and $38.17 \mathrm{mg}$, and 0.85 $\mathrm{mm}, 0.5 \mathrm{~mm}$ and $8.53 \mathrm{mg}$ respectively. On an average, the snails added $1.63,1.14,1.25,1.32$, $0.88,0.85,0.93,1.5,1.31,1.33,1.44$ and 1.14 $\mathrm{mm}$ to the length of the shell; $0.99,0.72,0.82$, $0.8,0.56,0.5,0.56,0.9,0.78,0.79,0.84$ and $0.71 \mathrm{~mm}$ to the breadth of the shell, and 27.42 , $8.53,14.16,16.36,17.64,16.01,14.76,26.33$,
$11.57,9.06,38.17$ and $23.57 \mathrm{mg}$ to the weight of the body of $L$. (R.) luteola considered for studies on July 1, August 1, September 1, October 4, November 4, December 6, 1990, January 7, February 5, March 3, April 2, May 1 and June 1, 1991 respectively, per week. Irrespective of snail stocks and the months an individual added, on the average $1.23 \pm 0.07$ $\mathrm{mm}, 0.75 \pm 0.04 \mathrm{~mm}$ and $18.63 \pm 2.41 \mathrm{mg}$ to the length of the shell, breadth of the shell and weight of the body respectively, per week. Of the 12 sets of experiments, the snails considered for studies on November 4, December 6, 1990, May 1 and June 1, 1991 exhibited faster rates of growth and attained maximum size and weight (Fig. 1). Of those, the snails of May 1991 batch, were largest in size (15.84 $\mathrm{mm}$ in shell length and $9.24 \mathrm{~mm}$ in shell breadth) and weight $(419.87 \mathrm{mg})$.

The snails became sexually mature (except April batch) at different ages in respect to the sets of experiments conducted (Table I). The snails of July and September batches attained sexual maturity at the age of 32 days while those taken for other sets of experiments needed more number of days but a maxinum of 53 days (as in case of the snails of December batch). Irrespective of snail batches and months of the year $L$. (R.) luteola required, on the average $40.73 \pm 2.01$ days for attainment of sexual maturity. The snails were of different sizes at the time of attainment of sexual maturity (Fig. 1, Table I). Such discrepancies have also been noted in the individuals who attained maturity even on the same day i.e., with same age.

The snails of different batches had a different length of reproductive period, from a minimum 1 day to a maximum 67 days, on an average $29.27 \pm 5.39$ days (Table I). Likewise, in these snails the postreproductive period ranged from 2 to 25 (average $8.46 \pm 2.24$ ) days. Though a batch of 100 zero-day old snails were considered for studies, 6 to 66 (average $39.0 \pm 6.14$ ) per cent individuals survived to take part in reproduction. The snails deposited a varying number of egg capsules as well as eggs in repect to the batches taken during each month (Table I). It is estimated that an individual snail can produce, on an average 0.1 to 9.33 egg capsules in its life span. The number of eggs laid per individual also varied with the snail batches (Table 1). A snail belonging to March batch laid, on the average $0.25 \mathrm{egg}$ (minimum) and that one belonged to May batch 
TABLE I

Data on the life cycle parameters of Lymnaea (Radix) luteola in respect to the months of the year July 1990 to June 1991.

[Experiments were conducted with 100 zero-day old individuals in each month]

\begin{tabular}{|c|c|c|c|c|c|c|c|c|c|c|c|c|c|}
\hline \multirow[t]{3}{*}{ Month } & \multicolumn{13}{|c|}{ Life cycle parameters } \\
\hline & \multicolumn{4}{|c|}{ Attainment of sexual maturity } & \multirow{2}{*}{$\begin{array}{l}\text { Repro- } \\
\text { ductive } \\
\text { period } \\
\text { (days) }\end{array}$} & \multirow{2}{*}{$\begin{array}{l}\text { Post- } \\
\text { repro- } \\
\text { ductive } \\
\text { period } \\
\text { (days) }\end{array}$} & \multirow{2}{*}{$\begin{array}{l}\text { Individuals } \\
\text { survived up } \\
\text { to the age of } \\
\text { attainment } \\
\text { of sexual } \\
\text { maturity }\end{array}$} & \multirow{2}{*}{$\begin{array}{l}\text { Number of } \\
\text { egg capsules } \\
\text { laid/indivi- } \\
\text { dual }\end{array}$} & \multirow{2}{*}{$\begin{array}{c}\text { Number of } \\
\text { eggs laid/ } \\
\text { individual }\end{array}$} & \multicolumn{2}{|c|}{ Hatching } & \multicolumn{2}{|c|}{ Longevity } \\
\hline & $\begin{array}{l}\text { Age } \\
\text { (days) }\end{array}$ & $\begin{array}{l}\text { Shell } \\
\text { length } \\
(\mathrm{mm})\end{array}$ & $\begin{array}{c}\begin{array}{c}\text { Shell } \\
\text { breadth }\end{array} \\
(\mathrm{mm})\end{array}$ & $\begin{array}{c}\text { Total } \\
\text { body } \\
\text { weight } \\
\text { (mg) }\end{array}$ & & & & & & $\begin{array}{c}\text { Time } \\
\text { required } \\
\text { (days) }\end{array}$ & $\begin{array}{l}\text { Percent } \\
\text { hatched }\end{array}$ & Range & Mean \pm S.E. \\
\hline \multicolumn{14}{|l|}{1990} \\
\hline July & 32 & 12.03 & 7.17 & 154.14 & 21 & 02 & 48 & 0.71 & 18.25 & 7.5 & 96 & $33-54$ & $47.23 \pm 0.59$ \\
\hline August & 35 & 11.00 & 7.00 & 131.00 & 10 & 25 & 60 & 0.10 & 2.22 & 8.0 & 96 & $36-69$ & $42.35 \pm 0.63$ \\
\hline September & 32 & 12.30 & 7.30 & 155.20 & 23 & 03 & 46 & 0.35 & 8.28 & 8.0 & 96 & $34-57$ & $46.39 \pm 0.90$ \\
\hline October & 35 & 11.08 & 6.50 & 119.00 & 22 & 11 & 49 & 0.10 & 1.71 & 8.0 & 95 & $38-67$ & $48.63 \pm 0.87$ \\
\hline November & 43 & 10.70 & 7.10 & 144.29 & 67 & 04 & 39 & 3.51 & 114.97 & 8.0 & 94 & $46-113$ & $82.31 \pm 2.06$ \\
\hline December & 53 & 12.30 & 7.56 & 205.29 & 49 & 09 & 62 & 1.57 & 60.10 & 8.0 & 93 & $55-110$ & $87.45 \pm 1.56$ \\
\hline \multicolumn{14}{|l|}{1991} \\
\hline January & 49 & 9.30 & 5.80 & 73.50 & 27 & 04 & 66 & 1.80 & 76.21 & 9.5 & 92 & $51-79$ & $67.27 \pm 0.76$ \\
\hline February & 45 & 13.11 & 8.54 & 231.93 & 28 & 03 & 27 & 1.41 & 48.74 & 9.0 & 91 & 47.75 & $59.04 \pm 1.54$ \\
\hline March & 44 & 11.00 & 6.80 & 128.00 & 01 & 21 & 08 & 0.13 & 0.25 & 8.0 & 95 & $45-65$ & $48.38 \pm 2.25$ \\
\hline April & - & - & - & - & - & - & - & - & - & 8.0 & 95 & $2-60$ & $19.42 \pm 1.16$ \\
\hline May & 37 & 11.64 & 7.06 & 148.93 & 48 & 03 & 06 & 9.33 & 443.67 & 7.0 & 95 & $45-87$ & $65.67 \pm 7.22$ \\
\hline June & 43 & 11.34 & 6.89 & 137.86 & 26 & 08 & 18 & 3.78 & 131.61 & 8.0 & 95 & $55-76$ & $66.00 \pm 1.11$ \\
\hline Range & $32-53$ & $9.3-13.11$ & $5.80-8.54$ & $73.50-231.93$ & 167 & $2-25$ & $6-66$ & $0.10-9.33$ & $0.25-443.67$ & $7.5-9.5$ & $91-96$ & $33-113$ & \\
\hline Mean \pm S.E. & $40.73 \pm 2.01$ & $11.50 \pm 0.29$ & $7.07 \pm 0.19$ & $148.1 \pm 12.07$ & $29.27 \pm 5.39$ & $8.46 \pm 2.24$ & $39.0 \pm 6.14$ & $2.07 \pm 0.79$ & $82.37 \pm 36.92$ & $8.08 \pm 0.17$ & $94.42 \pm 0.45$ & & $60.50 \pm 0.88$ \\
\hline
\end{tabular}

- indicates no trace of population. 
laid 443.67 eggs (maximum) during the lifetime. For a moment, if we ignore the months or the snail batches, an individual laid, on the average $82.37 \pm 36.92$ eggs (Table I). The hatching period of eggs varied from 7.5 to 9.5 (average $8.08 \pm 0.17$ ) days. The hatchability percentages also varied from 91 to 96 (average $94.42 \pm 0.45$ ) as shown in Table I. Irrespective of batches the snails survived for a period of 2-113 (average 60.5 \pm 0.88 ) days. From Table $I$ it is clear that the mean length of life of $L$. (R.) luteola varied from $19.42 \pm 1.16$ to 87.45 \pm 1.56 days so far as the snails belonging to different batches are concerned.

Since the rate of production of eggs in $L$. (R.) luteola varied with the individuals in respect to the batches of the snails considered for 12 sets of experiments an attempt was made to calculate the birth rate in respect to the age of the snails with the progress of months of the study year (Table II). Considering the time required for hatching eggs, and the length of inter-clutching period the age specific birth rate was calculated at an interval of 8 days. It is evident that the snails belonging to certain age groups took part in reproduction in each month except May. From an overall calculation, irrespective of months, it is revealed that the snails produced individuals at a maximum rate in their last phase of reproduction period (105112 days) while the same was minimum at the initial phase of reproduction (25-32 days) (Table II). Survival rates in $L$. (R.) luteola also varied with the ages and the months (Table III). The overall survival rates, irrespective of months have also been presented in Table III. Life table for $L$. (R.) luteola was constructed for different batches of snails in respect to months of the study year. It is evident that the zero-day old snails are expected to survive for a period of $14.16,19.52,21.6,23.04,28.08$, $29.76,30.8,31.6,32.72,41.52,53.92$ and 62.48 days if they were hatched on May 1, April 2, June 1, March 3, February 5, September 1, July 1, October 4, August 1, November 4, January 7 and December 6 of a year concerned respectively (Table IV). It is also clear that the expectation of life is only 4 days when the snails of July, August, September, October, November, December, January, February, March, April, May and June batches are of 48, $64,56,64,112,104,72,72,64,56,80$ and 72 days old respectively. Irrespective of months and snail batches the zero-day old individuals are expected to survive for a period of 32.03 days. But 64 days old individuals are expected to survive for a period of another 15.6 days and those that attained the age of 112 days are expected to survive for a period of 4 days more (Table IV).

On the basis of the data regarding birth rate and death rate over $100 \mathrm{~L}$. (R.) luteola during the period of 12 months of the study year the net rate of population growth in number has been calculated at an interval of 32 days and the figures are presented in Table V. Since the snails are unable to deposit the first egg capsule prior to the age of 32 days and the eggs hatch after 8 days, the numbers presented (7 to 83) against the months at the age of 32 days indicate the survival rates of the 100 zeroday old individuals selected for studies. With the progress of time the number of individuals may increase (sometimes decrease) at different rates in all months except March and April when there would be no snail individual on and from 96 days. From the calculation, it is evident that a total of 2,459,386 individuals would be seen on 352nd day if 100 zero-day old snails are taken for culture by the first week of May. Similarly, a varying number of snails could be seen on that day in respect to other months of a year (Table V). It is notable that for a batch of 100 zero-day old snails, if taken for studies on the first week of January, the number would reach 1768 on 96th day. This would follow a decline through ups and downs in number of individuals in the following months and 214 individuals could be seen on 352nd day (Table V). Based on the calculated data on the population size of $L$. (R.) luteola from a batch of 100 zero-day old individuals, an attempt was made to estimate the rate of recruitment of individuals at an interval of 32 days up to the period of 352 days in respect to 12 months of the study year. Irrespective of snail batches and months, there was no recruitment on 32nd day (Table VI). Also, there was no recruitment by the March and April snail batches during the period of next 64 days. The recruitment rates, in all other cases, at an interval of 32 days have been figured in Table VI. Likewise, the death rates have been calculated at an interval of 32 days and the results are presented in Table VII. The patterns of population growth in respect to recruitment and mortality rates during the period of 12 months of the study year, as regards to the batches of snails considered, have been shown in Fig. 2 A. Though there exist marked variations in the trend of population growth in respect to the snail batches considered it is 
Age-specific birth rate $\left(\beta_{\mathfrak{i}}\right)$ in Lymnaea (Radix) luteola in different months of the year July 1990 to June 1991

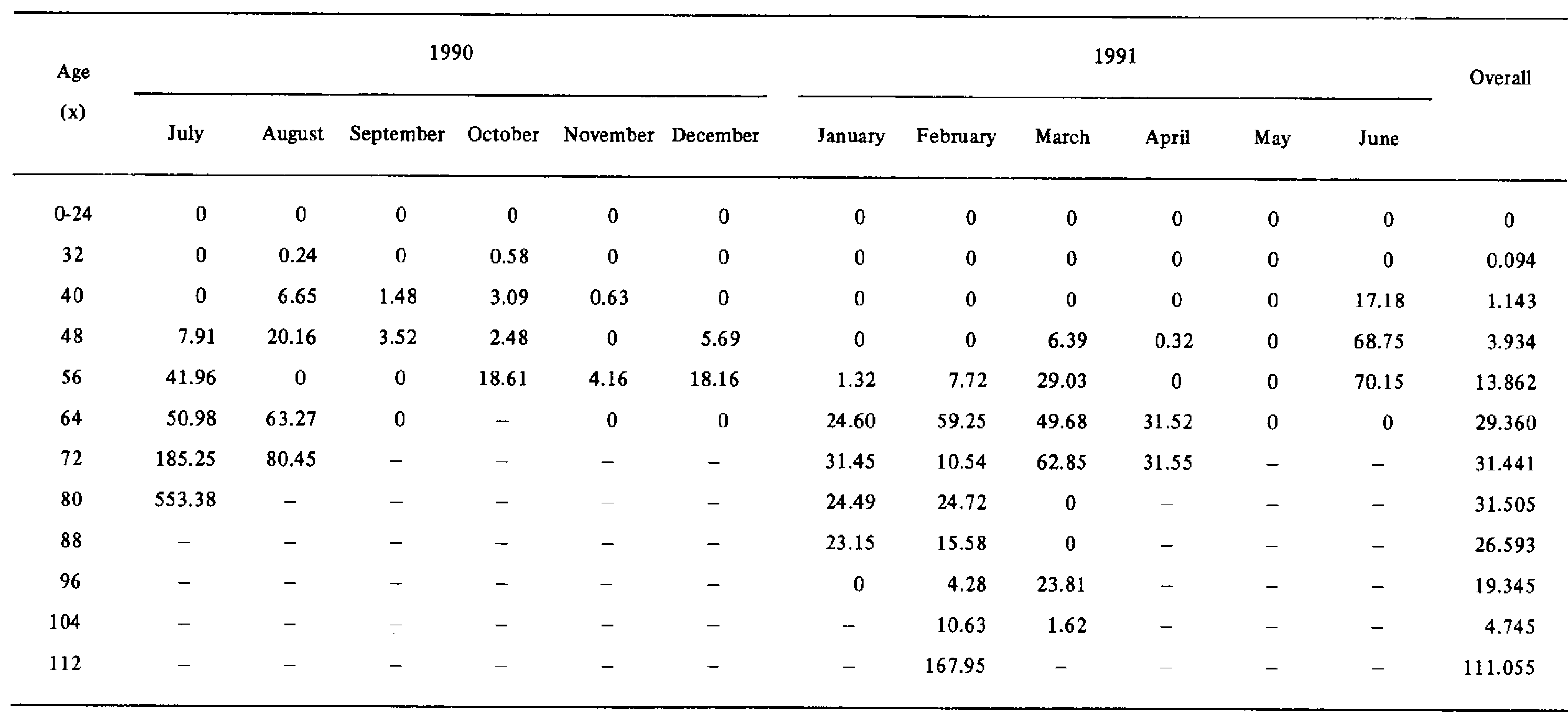

- : indicates no trace of population. 


\section{TABLE III}

Survival rate in Lymnaea (Radix) luteola in respect to the months of the year July 1990 to June 1991

\begin{tabular}{|c|c|c|c|c|c|c|c|c|c|c|c|c|c|}
\hline \multirow{2}{*}{$\begin{array}{l}\text { Age } \\
\text { (x) }\end{array}$} & \multicolumn{6}{|c|}{1990} & \multicolumn{6}{|c|}{1991} & \multirow{2}{*}{ Overall } \\
\hline & July & August & September & October & November & December & January & February & March & April & May & June & \\
\hline 0 & 0.99 & 0.96 & 1.00 & 0.94 & 0.90 & 0.96 & 1.00 & 1.00 & 0.81 & 0.87 & 0.55 & 0.70 & 0.89 \\
\hline 8 & 0.66 & 0.81 & 0.63 & 0.75 & 0.64 & 0.87 & 0.98 & 0.43 & 0.78 & 0.63 & 0.51 & 0.54 & 0.70 \\
\hline 16 & 0.88 & 0.91 & 0.89 & 0.80 & 0.85 & 0.90 & 0.91 & 0.88 & 0.83 & 0.60 & 0.54 & 0.61 & 0.83 \\
\hline 24 & 0.84 & 0.89 & 0.82 & 0.93 & 0.92 & 0.93 & 0.93 & 0.95 & 0.56 & 0.27 & 0.47 & 0.91 & 0.73 \\
\hline 32 & 0.91 & 0.96 & 0.73 & 0.80 & 0.87 & 0.91 & 0.96 & 0.82 & 0.92 & 0.35 & 0.67 & 0.86 & 0.95 \\
\hline 40 & 0.95 & 0.43 & 0.07 & 0.51 & 0.51 & 0.93 & 0.96 & 0.97 & 0.76 & 0.10 & 0.50 & 0.83 & 0.67 \\
\hline 48 & 0.94 & 0.00 & 0.33 & 0.05 & 0.17 & 1.00 & 0.92 & 0.94 & 0.64 & 1.00 & 0.33 & 0.60 & 0.72 \\
\hline 56 & 0.77 & - & 1.00 & 0.00 & 0.25 & 0.97 & 0.95 & 0.77 & 0.50 & 1.00 & 1.00 & 1.00 & 0.82 \\
\hline 64 & 1.00 & 0.08 & 0.00 & - & 0.00 & 0.00 & 0.87 & 0.97 & 0.21 & 0.25 & 0.00 & 0.00 & 0.61 \\
\hline 72 & 0.67 & 0.00 & - & - & - & - & 0.66 & 0.87 & 0.00 & 0.00 & - & - & 0.69 \\
\hline 80 & 0.00 & - & - & - & - & - & 0.57 & 0.67 & 0.00 & - & - & - & 0.62 \\
\hline 88 & - & - & - & - & - & - & 0.42 & 0.47 & 0.00 & - & - & - & 0.46 \\
\hline 96 & - & - & - & - & - & - & 0.00 & 0.40 & 0.27 & - & - & - & 0.30 \\
\hline 104 & - & - & - & - & - & - & - & 0.50 & 0.00 & - & - & - & 0.17 \\
\hline 112 & - & - & - & - & - & - & - & 0.00 & - & - & - & - & 0.00 \\
\hline
\end{tabular}


Expectation of life (in days) of Lymnaea (Radix) luteola in respect to the months of the year July 1990 to June 1991

\begin{tabular}{|c|c|c|c|c|c|c|c|c|c|c|c|c|c|}
\hline \multirow{2}{*}{$\begin{array}{l}\text { Age } \\
(x)\end{array}$} & \multicolumn{6}{|c|}{1990} & \multicolumn{6}{|c|}{1991} & \multirow{2}{*}{ Overall } \\
\hline & July & August & September & October & November & December & January & February & March & April & May & June & \\
\hline 0 & 30.80 & 32.72 & 29.76 & 31.60 & 41.52 & 62.48 & 53.92 & 28.08 & 23.04 & 19.52 & 14.16 & 21.60 & 32.03 \\
\hline 8 & 23.07 & 25.92 & 21.76 & 25.36 & 37.69 & 56.92 & 45.92 & 20.08 & 19.51 & 13.84 & 14.47 & 21.14 & 27.50 \\
\hline 16 & 25.05 & 22.97 & 24.19 & 24.69 & 48.28 & 56.48 & 38.78 & 33.40 & 15.94 & 11.56 & 16.57 & 27.58 & 29.78 \\
\hline 24 & 20.00 & 16.85 & 18.71 & 21.86 & 48.41 & 54.00 & 34.29 & 29.26 & 10.46 & 8.61 & 19.47 & 34.96 & 27.14 \\
\hline 32 & 15.00 & 10.48 & 13.91 & 15.23 & 44.36 & 49.52 & 28.48 & 22.67 & 7.59 & 12.89 & 29.14 & 29.90 & 27.70 \\
\hline 40 & 7.48 & 4.87 & 8.32 & 8.98 & 40.29 & 43.53 & 25.88 & 16.36 & 6.40 & 9.33 & 25.33 & 24.63 & 21.03 \\
\hline 48 & 4.00 & 9.33 & 4.42 & 5.74 & 35.16 & 37.35 & 18.55 & 12.32 & 20.00 & 6.67 & 21.60 & 17.78 & 21.31 \\
\hline 56 & - & 12.00 & 4.00 & 6.00 & 27.16 & 32.13 & 11.48 & 9.00 & 12.00 & 4.00 & 25.33 & 10.59 & 20.16 \\
\hline 64 & - & 4.00 & - & 4.00 & 19.78 & 25.61 & 5.67 & 6.00 & 4.00 & - & 17.33 & 4.61 & 15.60 \\
\hline 72 & - & - & - & - & 14.25 & 18.40 & 4.00 & 4.00 & - & - & 9.33 & 4.00 & 15.03 \\
\hline 80 & - & - & - & - & 11.62 & 12.50 & - & - & - & - & 4.00 & - & 12.00 \\
\hline 88 & - & - & - & - & 9.33 & 8.75 & - & - & - & - & - & - & 8.91 \\
\hline 96 & - & - & - & - & 8.80 & 6.13 & - & - & - & - & - & - & 6.80 \\
\hline 104 & - & - & - & - & 8.00 & 4.00 & - & - & - & - & - & - & 5.33 \\
\hline 112 & - & - & - & - & 4.00 & - & - & - & - & - & - & - & 4.00 \\
\hline
\end{tabular}

- : indicates no trace of population. 
TABLE V

Calculated net population size (in number) of Lymnaea (Radix) luteola at an interval of 32 days (taking in consideration of population size of the snails on the first week of each month of the year July 1990 to June 1991). [In all cases experiments were initiated with 100 zero-day old individuals on the firrst week of each month]

\begin{tabular}{|c|c|c|c|c|c|c|c|c|c|c|c|}
\hline \multirow{2}{*}{ Month } & \multicolumn{11}{|c|}{ Days } \\
\hline & 32 & 64 & 96 & 128 & 160 & 192 & 224 & 256 & 288 & 320 & 352 \\
\hline July & 48 & 633 & 335 & 514 & 312 & 1769 & 4193 & 80338 & 59210 & 216960 & 24312 \\
\hline August & 63 & 55 & 117 & 53 & 940 & 3157 & 17202 & 50325 & 6210 & 421 & 22520 \\
\hline September & 46 & 159 & 98 & 1148 & 1483 & 42271 & 32330 & 66646 & 5256 & 298998 & 720268 \\
\hline October & 52 & 34 & 23 & 567 & 815 & 4874 & 3283 & 268 & 10109 & 24988 & 80408 \\
\hline November & 45 & 935 & 3333 & 13453 & 66237 & 3530 & 203 & 8664 & 30653 & 113089 & 76067 \\
\hline December & 71 & 136 & 3256 & 4812 & 12286 & 1030 & 43717 & 106890 & 358635 & 310855 & 418165 \\
\hline January & 83 & 527 & 1768 & 24 & 0.39 & 24 & 75 & 298 & 160 & 377 & 214 \\
\hline February & 36 & 602 & 163 & 12 & 163 & 777 & 846 & 781 & 1336 & 643 & 9202 \\
\hline March & 29 & 01 & - & - & - & - & - & - & - & - & - \\
\hline April & 09 & 01 & - & - & - & - & - & - & - & - & - \\
\hline May & 07 & 493 & 1780 & 7287 & 4558 & 10145 & 5769 & 67501 & 122478 & 2290737 & 2459386 \\
\hline June & 21 & 867 & 808 & 738 & 1368 & 655 & 10259 & 31686 & 241986 & 617542 & 127894 \\
\hline
\end{tabular}

$-:$ indicates no trace of population.

TABLE VI

Recruitment rate (in number) in Lymnaea (Radix) luteola at an interval of 32 days (data represent the recruitment rate of the snails on the first week of each month of the year July 1990 to June 1991)

\begin{tabular}{lrrrrrrrrrrrr}
\hline & \multicolumn{10}{c}{ Days } \\
\cline { 2 - 11 } & 32 & 64 & 96 & 128 & 160 & 192 & 224 & 256 & 288 & 320 & 352 \\
\hline July & 0 & 721 & 196 & 662 & 262 & 1894 & 2831 & 82039 & 43428 & 333755 & 0 \\
August & 0 & 79 & 101 & 14 & 923 & 2510 & 15948 & 72946 & 6247 & 0 & 36340 \\
September & 0 & 207 & 42 & 1272 & 599 & 47217 & 30703 & 73968 & 0 & 537215 & 649090 \\
October & 0 & 40 & 0 & 552 & 1149 & 5228 & 4731 & 0 & 25338 & 20241 & 89623 \\
November & 0 & 906 & 2709 & 11552 & 98700 & 2840 & 0 & 13612 & 30465 & 112718 & 60644 \\
December & 0 & 79 & 5642 & 4058 & 17352 & 0 & 107203 & 87106 & 400603 & 299895 & 369354 \\
January & 0 & 479 & 3013 & 5 & 0 & 38 & 73 & 307 & 122 & 441 & 104 \\
February & 0 & 624 & 315 & 0 & 628 & 668 & 601 & 970 & 1056 & 333 & 8956 \\
March & 0 & 0 & 0 & - & - & - & - & - & - & - & - \\
April & 0 & 0 & 0 & - & - & - & - & - & - & - & - \\
May & 0 & 657 & 1815 & 6948 & 3500 & 11669 & 2880 & 72514 & 71154 & 2473330 & 2784465 \\
June & 0 & 856 & 365 & 960 & 1184 & 255 & 10211 & 24460 & 231421 & 861505 & 132810 \\
\hline
\end{tabular}

- : indicates no trace of population.

evident (Figs $2 \mathrm{~B}, \mathrm{C}$ ) that two peaks are a must in the trend of growth. Of the two peaks, March-April peak is much more pronounced than that of July-August.

The mean data on the hardness, chloride, alkalinity, $\mathrm{pH}$ and surface water temperature have been plotted in respect to months against the calculated overall data on population size (during first week of each month), recruitment rate and mortality rate in Table VIII.

The data obtained on the population size [p(x)] of $L .(R$.$) luteola in respect to months$ (x) have shown a marked variation in the trend of growth between the first 6 months and second 6 months of the study year. For statistical analysis, a simple exponential model $\mathrm{p}_{1}(\mathrm{x})=$ 


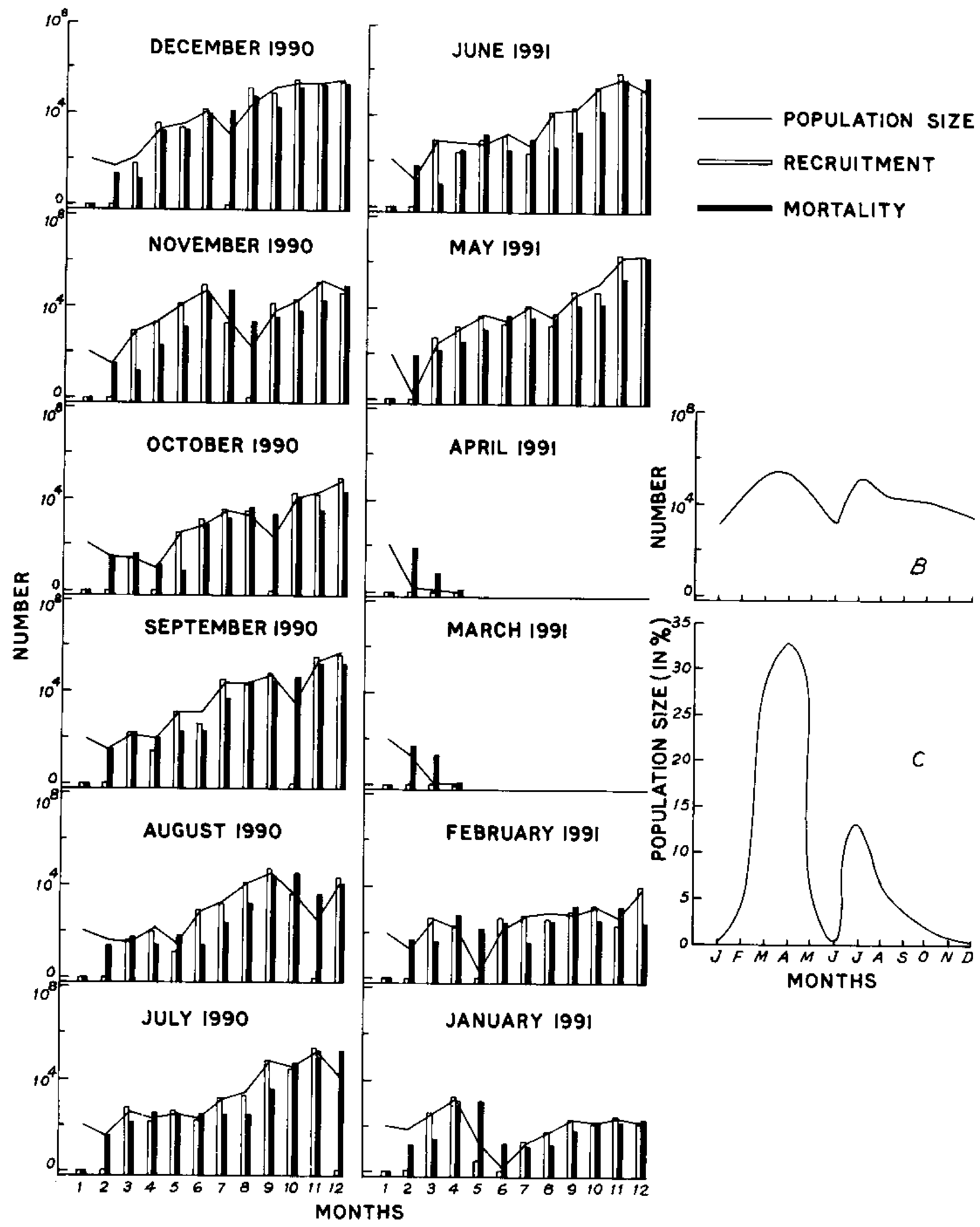

$A$

Fig. 2: pattern of population fluctuation in the pond snail Lymmaea (Radic) luteola during the period of 12 months of a year. A - In respect to the snail batches considered, the recruitment rate and mortality rate. B and C lrrespective of snail batches.

$\exp [2.566-0.6341 \mathrm{x}]$ was applied for the period of first 6 months (from July to December, 1990) and a double exponential curve $p_{2}(x)=$ $0.5394 \exp \left[-(\mathrm{x}-3.58)^{2} \mathrm{X} 0.9134\right]$ was fitted to the data collected during the period of next
6 months (from January to June, 1991). It is to be mentioned here that, at December, 1990 we used an average of $p_{1}(x)$ and $p_{2}(x)$ for calculation. The results of such statistical studies are presented in Table IX with a view to com- 
TABLE VII

Mortality rate (in number) in Lymnaea (Radix) luteola at an interval of 32 days (data represent the mortality rate of the snails on the first week of each month of the year July 1990 to June 1991)

\begin{tabular}{lrrrrrrrrrrrr}
\hline Month & \multicolumn{10}{c}{ Days } \\
\cline { 2 - 11 } & 32 & 64 & 96 & 128 & 160 & 192 & 224 & 256 & 288 & 320 & 352 \\
\hline July & 52 & 136 & 494 & 483 & 464 & 437 & 407 & 5894 & 64556 & 176005 & 192648 \\
August & 37 & 87 & 39 & 78 & 36 & 293 & 1903 & 39823 & 50362 & 5789 & 14241 \\
September & 54 & 211 & 103 & 222 & 264 & 6429 & 40644 & 39652 & 61390 & 243473 & 227820 \\
October & 48 & 58 & 11 & 08 & 901 & 1169 & 6322 & 3015 & 15497 & 5362 & 34203 \\
November & 55 & 16 & 311 & 1432 & 45916 & 65547 & 3327 & 5151 & 8476 & 30282 & 97666 \\
December & 29 & 14 & 2522 & 2502 & 9878 & 11256 & 64516 & 23933 & 148858 & 347675 & 262044 \\
January & 17 & 35 & 1772 & 1749 & 24 & 14 & 22 & 84 & 260 & 224 & 267 \\
February & 64 & 58 & 754 & 151 & 477 & 54 & 532 & 1035 & 501 & 1026 & 397 \\
March & 71 & 28 & 01 & - & - & - & - & - & - & - & - \\
April & 91 & 08 & 01 & - & - & - & - & - & - & - & - \\
May & 93 & 171 & 528 & 1441 & 6229 & 6082 & 7256 & 10782 & 16177 & 305071 & 2615816 \\
June & 79 & 10 & 424 & 1030 & 554 & 968 & 607 & 3033 & 21121 & 485949 & 622458 \\
\hline
\end{tabular}

-: indicates no trace of population.

\section{TABLE VIII}

Overall population size, recruitment rate and mortality rate (in \%) of Lymnaea (Radix) luteola in respect to hardness, chloride, $\mathrm{pH}$ and temperature of the water used in culture in different months of the year July 1990 to June 1991

\begin{tabular}{|c|c|c|c|c|c|c|c|c|c|c|}
\hline \multirow{2}{*}{ Month } & \multirow{2}{*}{$\begin{array}{l}\text { Population } \\
\text { size }\end{array}$} & \multirow{2}{*}{$\begin{array}{l}\text { Recruitment } \\
\text { rate }\end{array}$} & \multirow{2}{*}{$\begin{array}{l}\text { Mortality } \\
\text { rate }\end{array}$} & \multicolumn{3}{|c|}{ Hardness } & \multirow{2}{*}{ Chloride } & \multirow{2}{*}{ Alkalinity } & \multirow{2}{*}{$\mathrm{pH}$} & \multirow{2}{*}{ Temperature } \\
\hline & & & & $\mathrm{CaCO}_{3}$ & $\mathrm{Ca}^{++}$ & $\mathrm{Mg}^{++}$ & & & & \\
\hline July & 4.10 & 6.92 & 5.29 & 8.20 & 8.05 & 8.25 & 7.33 & 8.56 & 8.40 & 8.73 \\
\hline August & 9.45 & 7.58 & 4.10 & 6.38 & 6.45 & 6.35 & 4.79 & 8.52 & 8.30 & 8.86 \\
\hline September & 5.99 & 5.87 & 3.33 & 5.99 & 15.20 & 3.14 & 5.50 & 7.64 & 8.01 & 8.67 \\
\hline October & 4.20 & 3.50 & 7.00 & 6.32 & 13.81 & 4.00 & 6.21 & 7.99 & 7.35 & 8.31 \\
\hline November & 4.60 & 3.69 & 4.16 & 7.09 & 9.44 & 6.35 & 6.31 & 9.49 & 8.21 & 8.06 \\
\hline December & 0.08 & 0.04 & 0.16 & 7.74 & 7.13 & 7.93 & 7,13 & 8.52 & 9.02 & 6.96 \\
\hline January & 0.98 & 0.93 & 0.25 & 9.05 & 6.67 & 9.78 & 7.94 & 8.61 & 8.40 & 6.25 \\
\hline February & 1.78 & 1.01 & 0.32 & 10.30 & 8.51 & 10.85 & 7.84 & 8.60 & 8.34 & 7.73 \\
\hline March & 28.68 & 27.52 & 5.32 & 9.37 & 9.67 & 9.28 & 9.20 & 8.61 & 8.51 & 8.69 \\
\hline April & 35.14 & 37.45 & 50.78 & 10.08 & 3.91 & 12.00 & 13.59 & 8.17 & 8.33 & 9.27 \\
\hline May & 4.66 & 5.49 & 14.98 & 10.27 & 4.49 & 12.07 & 13.39 & 8.83 & 8.75 & 9.43 \\
\hline June & 0.34 & 0 & 4.31 & 9.21 & 6.67 & 10.00 & 10.77 & 6.46 & 8.38 & 9.04 \\
\hline
\end{tabular}

pare the same with the observed data. To find the goodness of fit of the overall observed population size with the expected values Chisquare test was applied.

Since, $\chi_{\text {cal }}^{2}=28.88, \chi_{0.001,11}^{2}=31.26$; $\chi_{\text {cal }}^{2}<\chi^{2} \quad 0.001,11 ; \mathrm{H}_{\mathrm{o}}$ is accepted at $0.1 \%$ level, i.e. at $0.1 \%$ level, the observed data fitted well to the model/curve used.
Based on the mean data presented in Table VIII correlation tests between population size and the life-cycle parameters, as well as abiotic factors were made to ascertain the impact of these parameters in regulating the population size. The ' $r$ ' values in connection with recruitment rate $(\mathrm{r}=0.9934)$, mortality rate $(\mathrm{r}$ $=0.7458)$, rate of net population gain $(r=$ $0.7189)$, chloride content of water $(r=0.7235)$ 
TABLE IX

Observed and expected population size (in \%) of Lymnaea (Radix) luteola in different months of the year July 1990 to June 1991

\begin{tabular}{lcc}
\hline & \multicolumn{2}{c}{ Population size } \\
\cline { 2 - 3 } Month & Observed & Expected \\
\hline July & 4.10 & 13.01 \\
August & 9.45 & 6.90 \\
September & 5.99 & 3.66 \\
October & 4.20 & 1.94 \\
November & 4.61 & 1.03 \\
December & 0.08 & 0.28 \\
January & 0.98 & 0.19 \\
February & 1.78 & 3.96 \\
March & 28.68 & 28.44 \\
April & 35.14 & 32.87 \\
May & 4.66 & 6.11 \\
June & 0.34 & 0.18 \\
\hline
\end{tabular}

and degrees of temperature in centrigade of the surface water $(r=0.4219)$ are acceptable with an indication of influence of these parameters on the population size of $L$. (R.) luteola. On the other hand, the role of hardness (as determined by measuring $\mathrm{CaCO}_{3}, \mathrm{Ca}^{++}$ and $\left.\mathrm{Mg}^{++}\right), \mathrm{pH}$ and alkalinity was not that much effective $\left[\mathrm{r}=0.285\left(\mathrm{CaCO}_{3}\right)\right.$, $-0.205\left(\mathrm{Ca}^{++}\right), 0.28\left(\mathrm{Mg}^{++}\right),-0.0788(\mathrm{pH})$ and 0.0635 (alkalinity)] in regulating the population dynamics of the snail species concerned. However, the some total effect of abiotic factors (hardness, alkalinity, chloride content, temperature and $\mathrm{pH}$ ) in determining population size is well established from the results of multiple correlation studies $(r=0.7785)$. Since both chloride and temperature, when considered separately, have shown marked influence over population size an attempt was made to ascertain the joint effect of these two factors in regulation of population density of $L$. (R.) luteola. For the same, the following equation was applied:

$$
P=-32.9952+1.2261 \mathrm{~S}+3.7333 \mathrm{~T}
$$

where $\mathbf{P}=$ population size; $\mathbf{S}=$ chloride content of water; $T=$ surface water temperature.

\section{DISCUSSION}

From the results the influence of growth and other biological parameters on the population dynamics of the snails $L$. (R.) luteola is well established. Indeed, growth as so defined is one of the essential characteristics that helps to differentiate between a living population and dead material of organic origin. The rate of growth of a population is expressed as the number of individuals by which the population increases divided by the amount of time that elapses while this population increase is taking place. To record the rate of growth of a population it is necessary to study the life cycle, natality, mortality and the factors influencing these parameters of the species taking part in composition of the said population. In all interactions between populations and their environments there is an exchange of energy. In course of interactions, a change in terms of biomass could well be recorded both at population level and individual level of the species concerned. Since individual's biomass is very much dependent on the rate of gain or loss in the growth parameters of the individual concerned it is essential to take the morphometric variations, including the total body weight of the individuals of a species into account, in course of studies on the population dynamics of the said species. As such, in the present programme the rates of growth in shell length, shell breadth and total body weight of the snails $L$. (R.) luteola have been recorded. It is evident that the zero-day old snails, considered for studies during the first week of each of the 12 months of the study year, have shown varying rates of growth throughout their life span. Except April batch, the snails (zero-day old) taken for studies in the remaining 11 batches became sexually mature between 9.3 and 13.11 mm shell length, 5.8 and $8.54 \mathrm{~mm}$ shell breadth and 73.5 and $231.93 \mathrm{mg}$ body weight. The individuals belonging to January batch though became sexually mature when they were 9.3 $\mathrm{mm}, 5.8 \mathrm{~mm}$ and $73.5 \mathrm{mg}$ in shell length, shell breadth and total body weight respectively, it is evident that they required 49 days to reach that stage of growth. Contrasting to this, the individuals belonging to February batch needed 45 days to attain the maximum size (13.11 $\mathrm{mm}$ in shell length and $8.54 \mathrm{~mm}$ in shell breadth) and weight $(231.93 \mathrm{mg})$ so far recorded at the attainment of sexual maturity. From the data it is expected that the snail individuals, irrespective of their birth dates, would be able to take part in reproduction with an average size of $11.5 \mathrm{~mm}$ in shell length, $7.07 \mathrm{~mm}$ in shell breadth and $148.1 \mathrm{mg}$ in body weight. But in reality it is observed that the snails of January, March, June, August, October and November batches attained sexual maturity prior to reaching that size and weight while the individuals of remaining batches 
(February, May, July, September and December) had to grow more beyond the average size and weight for taking part in reproduction. Such a situation raises a number of questions. It is not clear whether size or age determines the state of attainment of sexual maturity of the individuals of a species. From the results of the present studies it appears that the snails $L$. (R.) luteola, irrespective of batches, attained sexual maturity between 32 and 53 days after hatching. As per data, it is evident that the individuals of July and September batches required 32 days and those of December batch required 53 days for attainment of sexual maturity but they were almost equal in size so far shell length and breadth are concerned. This suggests that it is not the age but the size of the individuals that plays significant role in the process of attainment of sexual maturity of the snails $L$. (R.) luteola. Again, this conclusion is also questionable. Because if size of the individuals is the determining factor, then it would have not been possible for the snails of January, March, May, June, August, October and November batches to gain the said status being considerably smaller in size than the snails of July, September and December batches. Moreover, the individuals belonging to February batch would have not been wait for taking part in reproduction till the time of attainment of the shell size 13.11 $\mathrm{mm}$ in length and $8.54 \mathrm{~mm}$ in breadth. This indicates that there are some other factors that determine the time of attainment of sexual maturity of the individuals of a species, and the age and size, though important in this context, are simply qualifying parameters of the concerned individuals. Of the other factors, the physiological status of an individual seems to be the most important one. Of course, the physiological status of the individuals of a species is dependent on several factors like food, physico-chemical factors of water and the space. As the snails were fed with similar type of food throughout and the data obtained on $\mathrm{CaCO}_{3}, \mathrm{Ca}^{++}, \mathrm{Mg}^{++}$, chloride, alkalinity, $\mathrm{pH}$ and temperature of water used in the culture were almost within the same range at least for that length of time, the snails required to gain the ability for reproduction, the role of these factors in influencing the plysiological conditions for the purpose needed still remains obscure. Since the snails were exposed to a container with a fixed amount of pond water throughout the culture the space available to each individual was equal, at least on the first day. But with time, due to the death of indi- viduals of the concerned batch, the surviving individuals had the opportunity to enjoy the benefit of a larger space. Data indicate that 6 , $8,18,27,39,46,48,49,60,62$ and 66 individuals belonging to May, March, June, Febnuary, November, September, July, October, August, December and January batches respectively survived up to the age of attainment of sexual maturity. If space were the problem for achieving the desired growth rates, then the snail individuals belonging to May batch would have gained maximum size, and a gradually smaller sized individuals would have been found in the successive batches. But practically, this is not the case. Though, as per expectation, the individuals belonging to January batch are smallest in size $(9.3 \mathrm{~mm}$ in shell length) it is not the effect of crowding, rather a phenomenon of coincidence. Because, in December and August batches, the individuals, being 62 and 60 in number attained appreciably higher shell size $(12.3 \mathrm{~mm}$ and $11.0 \mathrm{~mm}$ shell length respectively) by enjoying almost the same space available to the snails of January batch. Though the snails of February batch reached maximum shell size while there were 27 individuals at the time of attainment of sexual maturity, this by no means justifies the existence of a space-induced problem because of attainment of $11.64 \mathrm{~mm}$ and $11.0 \mathrm{~mm}$ in length by the individuals of May and March batches respectively. Even, it is not possible to determine the 'exact space' needed by a $L$. (R.) Itteola for its maximum growth. Because the individuals belonging to July, September and October batches have attained different lengths even when they were exposed to the culture container providing almost equal space to the individuals.

Though studies on the growth rates of several freshwater snail species viz., Viviparus contectoides by Cleave \& Lederer (1932), Lymnaea humilis by McCraw (1961), Australorbis glabratus by Michelson (1961), Lymnaea luteola by Agarwal (1971), Cerithium muscarum, C. lutosum, C. eburneum and C. atratum by Houbrick (1974), Melania scabra by $\mathrm{Mu}-$ ley (1978), Viviparus georgianus by Browne (1978), Biomphalaria glabrata by Vianey-Liaud (1982, 1984, 1989), Tarebia granifera by Yong \& Perera (1983), Biomphalaria pfeifferi by Vianey-Liaud (1984), Bellamya bengalensis by Raut \& Bhattacharya (1986), Fossaria cubensis and Pseudosuccinea columella by Ferrer et al. (1989), and Brotia costula costula, Tarebia granifera and Melanoides tuberculata by 
Kruatrachue et al. (1990) are on record none of the previous workers has ever tried to note the variations in growth rates, if any, among the individuals of same species either produced by the same individual or different individuals in different seasons of the year. Such studies are essential to explain the phenomena involved with the growth of the snails.

Apart from the available information on the growth rates in shell length, breadth and body weight, and the age of attainment of sexual maturity, data have also been collected on the birth rates and death rates of $L$. (R.) luteola in respect to the snail batches considered for studies. After attainment of sexual maturity between 32-53 days of age the snails started deposition of egg capsules containing different number of eggs. The rate of production of egg capsule per individual varied with the snail batches. An individual belonging to May batch produced on an average $9.33 \mathrm{egg}$ capsules in its lifetime while another one belonging to August or October batch produced 0.10 capsule in its lifespan. Like production of egg capsules an individual belonging to May batch also produced, on the average, the highest number (443.67) of eggs while the lowest number $(0.25)$ of egg was produced by the individual belonging to March batch. This indicates that not only the size of the capsule varies with the snails but the number of eggs also varies with the capsule. Though a through account on the capsule production of snails is not available from the literature a good deal of information on the number of eggs per clutch is well documented. It ranges from 1-7 in Ferrissia rivularis (Burky, 1971), 2-3 in Ancylus fluviatilis (Bondesen, 1950; Calow, 1972, cited in Calow, 1978), 2-16 in Gyraulus convexiusculus (Raut, 1989), 2-38 (Raut, 1986), and 2-41 (Islam, 1977), in Indoplanorbis exustus, 3-12 in Acella haldemani (Morrison, 1932), 4 in Ancylus fluviatilis (Russell-Hunter, 1953; Geldiary, 1956), 5 in Planorbis albus (Bondesen, 1950), 5-11 in Physa fontinalis (Duncan, 1959) 5-144 in Lymnaea luteola (Raut \& Ghosh, 1985), 6-17 in Lymnaea humilis (McCraw, 1961), 6-144 in Lymnaea luteola forma typica (Raut, 1982), 7-9 in Lymnaea truncatula (Walton \& Jones, 1926), 8 in Anisus rotundatus (Bondesen, 1950), 9-18 in Valvata piscinalis (Cleland, 1954), 10 in Bithynia tentaculata (Lilly, 1953), 10-40 in Lymnaea palustris (Bondesen, 1950), 11-17 in Physa virgata (McMahon, 1975), 12-20 in Lymnaea peregra (Russell-Hunter, 1961a), 13 in Physa gyrina (De Witt, 1954), 15 in Physa fontinalis (Russell-Hunter, 1961a, b) and Lymnaea truncatula (Bondesen, 1950), 20 in Lymnaea palustris (Hunter, 1975), Physa fontinalis (Bondesen, 1950), Planorbis vortex (Bondesen, 1950) and Helisoma trivolvis (Eversole, 1974), 20-47 in Lymnaea elodes (Eisenberg, 1966), 30 in Planorbis corneus (Bondesen, 1950), 100150 in Lymnaea stagnalis (Bondesen, 1950; Berrie, 1965, 1966) and 200 in Lymnaea peregra (Bondesen, 1950). In the present study the number of eggs per capsule was ranged from 2-112, irrespective of the snail batches considered. However, from the overall number of eggs produced by the snails of a batch it is clear that an individual belonging to May batch produced, on an average $47.55 \mathrm{eggs}$ and that of March batch produced 1.92 eggs per capsule. Though it is sure that the rate of production of eggs per capsule plays a vital role in building up the population of a species the degree of egg productivity of an individual is very much influenced by its length of reproductive period. From the results it appears that the snails $L$. (R.) luteola have, on the average 1-67 days for reproduction. Individuals belonged to November batch produced eggs for a period of 67 days while those of December and May batches had 49 and 48 days for reproduction, respectively. In other batches (except March batch) the same ranged from 10 to 28 days. The snails belonging to March batch had only one day for egg production. Since the number of eggs produced by an individual belonging to May batch (having 48 days for production of eggs) was higher than that produced by the individual belonging to November batch (having 67 days for production of eggs) it is apparent that the rate of egg production depends not only on the length of the reproductive period but also on other factors like clutch size and frequency of clutching. Whatever be the factors it is well evident that in $L$. (R.) Iuteola the length of reproductive period, the frequency of clutching and the number of eggs per clutch vary with the batches of the snails considered for studies. The impact of these factors is tremendous so far the birth rate of the snail species is concerned. Depending on the length of reproductive period of an individual of a batch there exists the possibility of getting offspring at different rates in different months of a year. The snails of each and all the 12 batches would enter into the next month after 30 days of age. Since egg laying starts between 32 and 53 days it is sure that these snails would deposit eggs during the 
period of 30 days of the next month. Accordingly, they would enter subsequently into the next month and deposition of eggs would be continued up to the limit of reproduction period of the individuals concerned. As the life span of $L$. (R.) luteola ranges from 33 to 113 (average 60.5) days and the reproductive period is recorded for a length of 1-67 (average 29.27) days it is certain that the snails would complete their egg-laying within a period of 67 days following attainment of sexual maturity. This indicates that the snails, at best, would add to the population for a maximum period of next two months and a week in the third month. But in cases when the life span as well as the duration of reproduction period of the snails are short there would be little or no possibility of the snails entering into the second or third month as the case may be. Since some of the snails of April batch surviving for a period of 60 days failed to attain sexual maturity by that age and the sirails belonging to March batch had a maximum life span of 65 days there was no possibility of occurrence of snail individuals for taking part in recruitment during the month of May. This explains why birth rate was nil during that month. This could be explained more clearly if we consider the birth rates during February. In this month the individuals belonging to three different age groups, coming from three different snail batches considered in earlier months, took part in reproduction. Since the snails belonging to November and December batches had longer both lifespan and reproductive period, they with the increase of age entered into February along with the snails of January batch. The snails of these three batches, with a difference of 30 days in age from batch to batch, started deposition of eggs simultaneously, according to their potentiality during the month of February and the rates were high. Irrespective of months birth rate in $L$. (R.) luteola is highest in the aged individuals. Production of maximum number of eggs by the aged individuals is also customary in the land snail Achatina fulica (Raut, 1991).

In course of addition of new individuals to the population a gradual decline in the number of individuals due to death, has also been recorded in respect to snail batches. From the calculations it is clear that the survival rate in $L$. (R.) luteola varies with the months and ages of the snails. This phenomenon is more clear from the data obtained on the expectation of life of an individual in respect to month and age. As per data of the life table, it is expected that the 48 days old snails of July, August, September, October, November, December, January, February, March, April, May and June batches are expected to survive for a period of $4.00,9.33,4.42,5.74,35.16,37.35,18.55$, $12.32,20.00,6.67,21.60$ and 17.78 days more while irrespective of batches they are expected to survive for 21.31 days more. Likewise, the 112 days old snails are expected to live for a period of another 4 days.

The trend of population growth of a species is mostly dependent on its birth rate and death rate. In $L$. (R.) luteola the birth rate and death rates varied with the individuals of the batches concerned. It is interesting to note that a batch of 100 zero-day old snails if considered for culture during July, August, September, October, November, December, January, February, May and June would present 24312, $22520,720268,80408,76067,418165,214$, 9202,2459386 and 127894 individuals by the end of 352 days. Though by the end of 352 days only 214 individuals are expected from 100 zero-day old snails of January batch they increased to 1768 within a period of 96 days. As the mortality rate during the next few weeks was very high the number was reduced to 24 by the next 32 days. Because of high mortality rate and no possibility of recruitment the snails of March and April batches were unable to build up a population. Simply, it appears that there exists no mechanism of a gradual increasing trend of population growth in this species occurring in Calcutta, India.

The results of correlation studies between population size and abiotic factors though indicating the influence of temperature more than the chloride in regulating the population size of $L$. (R.) luteola no marked variations in these parameters have been noted in different months of the year. If the influence of temperature is effective in determining the population size in respect to the rates of recruitment and mortality for the months of December and January the same is not true for the populations of other months of the year.

Of the several dynamic features that a population displays, the most fundamental is that of growth, the capacity for increase in individual numbers (Boughey, 1973). Such capacity is very much dependent on several biotic and abiotic factors (Lomnicki, 1969; 
Odum, 1971; Kendeigh, 1975; Solomon, 1977; Raut, 1981, 1991). Since the abiotic factors were almost similar throughout the culture of $L$. (R.) luteola the characteristic changes noted in body growth rates, natality rates and mortality rates in different snail batches seem to be the determining criteria for the specific pattern of growth of the population generated by the individuals of a definite snail batch. It is obvious that the variations in the pattern of growth of the snail population are due to the evolved 'dynamic' by the member of a definite snail batch as a result of their interactions with the environment. Since the degree of interactions varies with time, in respect to the age and physiological status of the animals concerned, the evolved 'dynamic' would vary accordingly. It is that 'dynamic' which has given rise to the characteristic pattern of 'dynamics' in population growth of $L$. (R.) luteola in respect to the snail batches concerned. As birth and death is a continuous process in this snail population it is expected that the nature of 'dynamic' would vary from time to time with incoming new group of individuals. If we ignore the 'dynamic' in respect to the group of individuals of the species it is the average some total evolved 'dynamic' due to the activities of all the available individuals in respect to time that regulates the 'population-dynamics' of $L$. (R.) luteola. The variations in evolved 'dynamic' by different groups of individuals of the species may be accounted from the fact of variations involved with the 'strains' of the individuals concerned. This may be termed as 'genotypic variation' as has been suggested by Boughey (1973). Since variations in life cycle strategies in snail species in respect to 'strains' have been noted by the workers (Newton, 1954, 1955; Paraense, 1955; Richards, 1967, 1973; Cridland, 1970; Scherrer et al., 1976; VianeyLiaud, 1989) it is sure that the nature of 'dynamic' also varies with the 'strains' of the snail species. For the said reason, an understanding of the 'dynamic' aspects of the economically important snail species is a must with a view to develop an effective management policy.

\section{ACKNOWLEDGEMENTS}

To the Head of the Department of Zoology, Calcutta University for the facilities provided. To Mr T. K. Ghara, Department of Statistics, Presidency College, Calcutta for assistance in statistical analysis of the data.

\section{REFERENCES}

AGARWAL, H. P., 1971. Growth indices of Lymnaea luteola. J. Zool. Soc. Ind., 23: 119-123.

BERRIE, A. D., 1965. On the life cycle of Lymnaea stagnalis (L.) in the west of Scotland. Malacol. Soc. London, Proc., 36: 283-295.

BERRIE, A. D., 1966. Growth and seasonal variation in reproductive organs of Lymnaea stagnalis (L.). Malacol. Soc. London, Proc., 37: 83-92.

BONDESEN, P., 1950. A comparative morphologicalbiological analysis of the egg capsules of freshwater pulmonate gastropods. Hygrophila, Basommatophora, Pulmonata. Nat. Jutland, 3: 1-208.

BOUGHEY, A. S., 1973. Ecology of populations. 2nd ed. Macmillian Publishing Co., Inc., New Yotk, $\mathrm{X}+182 \mathrm{p}$.

BROWNE, A. R., 1978. Growth, mortality, fecundity, biomass and productivity of four lake populations of the prosobranch snail, Viviparus georgianus. Ecology, 59: 742-756.

BURKY, A. J., 1971. Biomass turnover, respiration, and interpopulation variation in the stream limpet Ferrissia rivularis (Say). Ecol. Monogr., 41: 235 251.

CALOW, P., 1978. The evolution of life-cycle strategies in freshwater gastropods. Malacologia. 17: 351364.

CLEAVE, H. J. van \& LEDERER, L. G,, 1932. Studies on the life cycle of the snail Viviparus contectoides. J. Morphol., 53: 499-522.

CLELAND, D. M., 1954. A study of the habitats of Valvata piscinalis (Muller) and the structure and function of alimentary canal and reproductive system. Proc. malac. Soc. London, 30: 167-203.

CRIDLAND, C. E., 1970. Susceptibility of the snail Biomphalaria alexandrina from the UAR and the Sudan to infection with a strain of Schistosoma mansoni from Tanzania. Bull. Wld. Hlth. Org., 43: 809-815.

DE WITT, R. M., 1954. Reproduction, embryonic development and growth in the pond snail, Physa gyrina Say. Trans. Amer. Micr. Soc., 73: 124-137.

DUNCAN, C. J., 1959. The life cycle and ecology of the freshwater snail Physa fontinalis (L.). J. Anim. Ecol., 28: 97-117.

EISENBERG, R. M., 1966. The regulation of density in a natural population of the pond snail, Lymnaea elodes. Ecology, 47: 889-906.

EVERSOLE, A. G., 1974. Fecundity in the snail Helisoma trivolvis: experimental, bioenergetic and fisld studies. Ph.D. Thesis, Syracuse University.

FERRER, J. R.; PERERA, G.; YONG, M. \& AMADOR, O., 1989. Life tables of Fossaria cubensis and Pseudosuccinea columella, intermediate hosts of Fasciola hepatica in Cuba. J. Med. \& Appl. Malacol., I: 189-194.

GELDIARY, R. 1956. Studies on local populations of the freshwater limpet Ancylus fluviatilis Muller. $J$. Anim. Ecol., 25: 389-402.

GOON, A. M.; GUPTA, M. K. \& DASGUPTA, B., 1987. Fundamentals of Statistics. Vol. I. The World Press Private Ltd., Calcutta, XV+664 p.

HOUBRICK, R. (JOSEPH, R.), 1974. Growth studies on the genus Cerithium (Gastropoda: Prosobranchia) 
with notes on ecology and microhabitats. The $\mathrm{Nau}$ tilus, 88: 14-27.

HUNTER, R. D., 1975. Growth, fecundity and bioenergetics in three populations of Lymnaca palustris in upstate New York. Ecology, 56: 50-63.

ISLAM, K. S., 1977. A note on the life-cycle of Indoplanorbis exustus (Deshayes) under laboratory conditions. Ind. J. Anim. Sci., 47: 374-376.

KENDEIGH, S. C., 1975. Ecology with special reference to animals and man. Prentice-Hall of India Pvt. Ltd., New Delhi, India, IV+477 p.

KRUATRACHUE, M.; UPATHAM, E. S.; VICHASRI, S. \& BAIDIKUL, V., 1990. Culture method for the thiarid snails Brotia costula costula, Tarebia granifera and Melanoides tuberculata (Prosobranchia: Mesogastropoda). J. Med. \& Appl. Malacol., 2: 9399.

LILLY, M. M., 1953. The mode of life and the structure and functioning of the reproductive ducts of Bithynia tentaculata (L.). Proc. malac. Soc. London, 30: 87. 100.

LOMNICKJ, A., 1969. Individual differences among adult members of a snail population. Nature (London), 223: 1073-1074.

McCRAW, B. M., 1961. Life history and growth of the snail, Lymnaea humilis Say. Trans. Am. micros. Soc., 80: 16-27.

McMAHON, R. F., 1975. Effect of artificially elevated water temperatures on Physa virgata. Ecology, 56: $1167-1175$.

MICHELSON, E. H., 1961. The effects of temperature on growth and reproduction of Australorbis glabratus in the laboratory. Am. J. Hyg., 73: 66-74.

MORRISON, J. P. E., 1932. Studies on the life history of Acella haldemani ("Desh" Binney). Trans. Wiscon. Acad. Sci. Arts and Letters, 27: 397-413.

MULEY, E. V., 1978. Studies on growth indices of the fresh water Prosobranch, Mclania scabra. Hydrobiol., 58: 137-143.

NEWTON, W. L., 1954. Albinism in Australorbis glabratus. Proc. Helmintol. Soc. Wash., 40: 183-186.

NEWTON, W. L., 1955. The establishment of a strain of Australorbis glabratus which combines albinism and high susceptibility to infection with Schistosoma mansoni. J. Parasitol., 4J: 526-528.

ODUM, E. P., 1971. Fundamentals of Ecolo1y. W. B. Saunders Co., Philadelphia, 574 p.

PARAENSE, W., 1955. Self and cross-fertilization in Australorbis glabratus. Mem. Inst. Oswaldo Cruz, 53: $285-291$.

RAUT, S. K., 1981. Population interaction among freshwater snails. Proc. Symp. Ecol. Anim. Popul., Pt. 2: 163-173.

RAUT, S. K., 1982. Disease transmitting snails. I. Population studies of Lymnaea luteola forma typica. P. R. S. Thesis, Calcuta University.

RAUT, S. K, 1986. Disease transmitting snails. II. Population studies of Indoplanorbis exustus (Deshayes). First Year's P. R. S. Thesis, Calcutta University.

RAUT, S. K., 1989. Disease transmitting snails. III.
Population studies of Gyraulus convexiusculus (Hutton). Second Year's P. R. S. Thesis, Calcutta University.

RAUT, S. K., 1991. Population dynamics of the pestiferous snail Achatina fulica Bowdich. Malacol. Rev., 24: 79.106.

RAUT, S. K. \& BHATTACHARYA, R., 1986. Growth indices of banded pond snail Bellamya bengalensis. Environ. \& Ecol., 4: 295-296.

RAUT, S. K. \& GHOSH, U., 1985. Egg capsules of some fresh water vector snails. Environ. \& Ecol., 3: 214-217.

RICHARDS, C. S., 1967. Genetic studies on Biomphalaria glabratus (Basommatophora: Planorbidae), a third pigmentation allele. Malacologia, 5: 335-340.

RICHARDS, C. S., 1973. Pigmentation variations in Biomphalaria glabrata and other Planorbidae. Malacol. Rev., 6: 49-51.

RUSSELL-HUNTER, W. D., 1953. On the growth of the freshwater limpet Ancylus fuviatilis Muller. Proc. zool. Soc. London, 123: 623-636.

RUSSELL-HUNTER, W. D., 1961a. Annual variations in growth and density in natural populations of freshwater snajls in the West of Scotland. Proc. zool. Soc. London, 136: 219-253.

RUSSELL-HUNTER, W. D., 1961b. Life-cycles of four freshwater snails in limited populations in Loch Lomond, with a discussion of intraspecific variation. Proc. zool. Soc. London, 137: 135-171.

SCHERRER, J. F.; de CHQUILOFF, M. A. G. \& FREITAS, J. R., 1976. Estudo comparativo da reprodução em quatro variedades geneticas de Biomphalaria glabrata (Say, 1818). I-Fecundidade. Rev. Inst. Med. Trop. S. Paulo, 18: 315-321.

SOLOMON, M. E., 1977. Population Dynamics. Studies in Biology, No. 18. Edward Arnold Ltd., London, $67 \mathrm{p}$.

TRIVEDY, R. K. \& GOEL, P. K, 1986. Chemical and Biological Methods for Water Pollution Studies. Environmental Publications, Karad (INDIA). Series in methodology, 1, $250 \mathrm{p}$.

VIANEY-LIAUD, M., 1982. Effects des hautes temperatures sur la reproduction de Biomphalaria glabrata (Mollusca: Basommatophora). (Proc. 7th Intern. Malacol. Congr.). Malacologia, 22: 159-165.

VIANEY-LIAUD, M., 1984. Effects of starvation on growth and reproductive apparatus of two immature freshwater snails Biomphalaria pfeifferi and Biomphalaria glabrata (Gastropoda: Planorbidae). Hydrobiol., 109: 165-172.

VIANEY-LIAUD, M., 1989. Growth and fecundity in a black-pigmented and an albino strain of Biomphalaria glabrata (Gastropoda: Pulmonata). Malacol. Re'v., 22: 25-32.

WALTON, C. L. \& JONES, N. W., 1926. Further observations on the life-history of Limnaea truncatula. Parasitology, 18: 144-147.

YONG, M. \& PERERA, G., 1983 [1986]. Growth of Tarebia granifera in natural habitat. Proc. 8 th $\mathrm{In}$ tern. Malacol. Congr., Budapest, p. 301-304. 